\title{
Predictors of local malaria outbreaks: an approach to the development of an early warning system in Colombia
}

\author{
Julio César Mateus ${ }^{1,2,4 /+}$, Gabriel Carrasquilla ${ }^{3,4}$ \\ ${ }^{1}$ División Salud, Fundación FES Social, Cali, Colombia \\ ${ }^{2}$ Escuela de Salud Pública, Universidad del Valle, Cali, Colombia \\ ${ }^{3}$ Centro de Estudios e Investigación en Salud, Fundación Santa Fe de Bogotá, Bogotá, Colombia \\ ${ }^{4}$ Centro Latino Americano de Investigación en Malaria, Cali, Colombia
}

\begin{abstract}
Risk factor surveillance is a complementary tool of morbidity and mortality surveillance that improves the likelihood that public health interventions are implemented in a timely fashion. The aim of this study was to identify population predictors of malaria outbreaks in endemic municipalities of Colombia with the goal of developing an early warning system for malaria outbreaks. We conducted a multiple-group, exploratory, ecological study at the municipal level. Each of the 290 municipalities with endemic malaria that we studied was classified according to the presence or absence of outbreaks. The measurement of variables was based on historic registries and logistic regression was performed to analyse the data. Altitude above sea level [odds ratio (OR) 3.65, 95\% confidence interval (CI) 1.34-9.98], variability in rainfall (OR 1.85, 95\% CI 1.40-2.44) and the proportion of inhabitants over 45 years of age (OR 0.17, 95\% CI 0.08-0.38) were factors associated with malaria outbreaks in Colombian municipalities. The results suggest that environmental and demographic factors could have a significant ability to predict malaria outbreaks on the municipal level in Colombia. To advance the development of an early warning system, it will be necessary to adjust and standardise the collection of required data and to evaluate the accuracy of the forecast models.
\end{abstract}

Key words: malaria - risk factor - public health surveillance - ecological analysis - municipal outbreaks - forecast

Surveillance systems in public health (SSPH) have been a useful tool for community health practice. These systems have supported promotion and prevention activities and the evaluation of programs and projects in public health (Teutsch \& Churchill 2000). Until a few years ago, most SSPH were focused on morbidity and mortality only, but in recent years there has been a growing interest in monitoring risk factors. Monitoring these risk factors is expected to improve the predictive ability of the SSPH, such that public health staff could obtain additional support to implement and evaluate interventions in a timely manner.

Timely intervention and evaluation is preferred. The surveillance of risk factors may predict morbidity and mortality in advance and public health staff will be able to alert at-risk populations and to initiate early activities to avoid or reduce cases and deaths. Additionally, the surveillance of risk factors identifies trends and the distribution of specific risk factors (Teutsch \& Churchill 2000) for various health conditions. These systems could be used to evaluate the effectiveness of interventions before changes in morbidity or mortality occur (Morabia 1996, Rehle et al. 2004). Thus, the de-

Financial support: Fundación FES, COLCIENCIAS, CLAIM/NIAID/ICEMR (3207-04-166-97, U19AI089702)

+ Corresponding author: jcmateus@fundacionfes.org

Received 31 March 2011

Accepted 29 June 2011 velopment and implementation of a surveillance system of risk factors or an early warning system (EWS) for malaria will identify and delineate areas with greatest risk of outbreaks and provide weeks or months of advance warning (Chaves \& Pascual 2007).

For several decades, the incidence of malaria has been studied to model trends and predicts the future incidence of disease. Thus, studies have been conducted to determine the relationship between the incidence of malaria in a population and meteorological conditions and other environmental factors such as the vegetation index, land use and altitude (Singh et al. 1996, Bouma et al. 1997, Bouma \& Dye 1997, Thompson et al. 1997, Kleinschmidt et al. 2000, Mauny et al. 2004, Ruiz et al. 2006, Chaves \& Pascual 2007).

Almost all mathematical models developed in these studies have forecasted with an accuracy of $0.50-0.80$ (Chaves \& Pascual 2007), but very few have achieved higher reliability when using vegetation indexes (Gomez-Elipe et al. 2007). Another common feature of these studies is that the data needed to model malaria incidence require active field collection, an expensive and time-consuming endeavour. Additionally, these mathematical models are complex and the use of these models in local settings could be limited. Therefore, this study aimed to illustrate the use of a low-cost methodology to advance the construction of an EWS for local malaria outbreaks using a mathematical model that may be more appropriate for local use. Additionally, we used population variables that are periodically recorded by Colombian government institutions from different sectors to avoid expensive collection procedures. 


\section{SUBJECTS, MATERIALS AND METHODS}

Study population - Approximately $30 \%$ of the 44 million inhabitants of Colombia live in areas in which malaria transmission has been documented. From 19871994, the incidence of malaria increased in 13 of the 32 departments of the country (Databases provided by the Ministry of Health and the National Institute of Health of Colombia). This study selected 290 municipalities with a history of malaria that were located $\leq 1,500$ meters above sea level (masl). To be selected, the municipalities must have reported continuous cases during the study period. Municipalities with discontinuous reporting or epidemiological silence were excluded.

Type of study - We conducted an ecological study with multiple groups (Morgenstern 2008), in which a case was defined as a municipality with at least one malaria outbreak from 1987-1994, but that had good malaria control otherwise. The unit of analysis was the municipality and all variables were measured using local features only. No individual variables or other ecological levels were included in the analyses.

Construction of the independent variables - The variables, including age distribution, proportion of households with unmet basic needs (UBN) and proportion of the population without education were obtained from national censuses of 1985 and 1993 (DANE 1985, 1996). Using this information, demographic and socioeconomic variables were constructed for three different age groups: < five years, five-14 years and 15-45 years of age. The growth rate of the local population and of each age group between the two censuses was included. In addition, the change in the proportion of households with UBN between 1985-1993 was included.

Using records and publications from the Institute of Hydrology and Environmental Studies (IDEAM) and the Geographic Institute Agustin Codazzi (IGAC 1996), environmental and geographical variables were obtained. Using IGAC projections of monthly rainfall averages from 1987-1994, it was possible to estimate standard errors of those averages for 96 months in every municipality. In this way, the variability of monthly rainfall was measured across the study period. In addition, the area of each municipality in square kilometres, the population density and the altitude in masl were taken.

Per capita expenses by municipality were obtained by using information on public investment and population size. Also, the increase in this investment from 19921996 was calculated using the recommended adjustment for inflation, with 1998 as the base year (Lora 2005).

The provision of health services was calculated by multiplying the number of health care workers in governmental institutions times 250 working days per year divided by the local population. The change in this variable from 1987-1996 was also included.

Construction of the dependent variable - The dependent variable was the presence of a local malaria outbreak. An outbreak was defined as a point in time when the proportion of cases in a municipality $\left(n_{i}\right)$ to the total number of department (state) cases $(\mathrm{Ni})$ per year showed statistical differences between years using the Chi-square test $\chi^{2}$ (Fleiss 1981).

Finally, we verified our results graphically and ruled out any potential error in the analysis that might have resulted from changes in the trends due to any of the following three situations: (i) a greater increase in the number of cases in the department in relation to the municipality, which could produce a significant $\chi^{2}$ result even without an increase in the number of cases in the municipality, (ii) a reduction in the number of cases in the department without a change in the number of cases reported in the municipality and (iii) an increase in the number of cases in the department and a proportional increase in the number of cases in the municipality, a situation that could produce a non-significant $\chi^{2}$ result even when there was actually an increase in the municipal incidence.

Analyses - All variables were constructed and stored in Epi-Info 6.03b version (Centre for Disease Control and Prevention, Atlanta, GA, USA) and analysed with Stata $^{\circledR}$ (Stata Statistical Software, College Station, TX). We performed logistic regression univariate and multiple analyses (Hosmer \& Lemeshow 1989). To construct the final model, the independent variables with a $p$ value of $\leq 0.25$ in the bivariate analysis were included. For the final model, the backward stepwise technique with pe $=$ 0.05 and $\mathrm{pr}=0.15$ was used. We evaluated the presence of potential confounders and effect modifiers between the final variables and the fit of the model was assessed with the Hosmer-Lemeshow test (Lemeshow \& Hosmer 1982). Finally, we estimated the area under the receiver operating curve (ROC) (Fletcher \& Fletcher 2005) of the final variables to determine their predictive capacity as independent variables and in combination.

\section{RESULTS}

Two hundred and sixty-seven (92\%) of the $290 \mathrm{mu}-$ nicipalities reported continuous malaria cases throughout the study period. Of those municipalities with continuous cases, $176(65.9 \%)$ had malaria outbreaks. Graphical verification and the $\chi^{2}$ test confirmed $99.9 \%$ of the malaria outbreaks. The greatest risk of outbreaks occurred in municipalities with administrative headquarters (AHM) located at altitudes between 2001,500 masl. Additionally, municipalities with a high proportion of households with UBN, a high proportion of the population without education in 1993 and greater variability in monthly rainfall had a significantly greater risk of malaria outbreaks. Municipalities with a higher proportion of inhabitants older than 45 years have a significantly lower risk of outbreak. For each increase by five percentage points in the proportion of the population older than 45 years, the chance of an outbreak decreased by $77 \%$ (Table I).

No significant association was found between local outbreaks and per capita funds transferred from the central government to the municipality [odds ratio (OR) 1.00, 95\% confidence interval (CI) 1.00, 1.00] or between local outbreaks and the amount of hours worked by health personnel per capita (OR 1.01, 95\% CI 0.95, 1.06) (Table I). 


\section{TABLE I}

Univariate analysis between the municipal variables and the risk of epidemic outbreaks of malaria in Colombian municipalities, 1987-1994

\begin{tabular}{|c|c|c|c|}
\hline \multirow{2}{*}{$\frac{\text { Variables }^{a}}{\text { Altitute }^{b, c} \leq 200}$} & \multirow{2}{*}{$\frac{\mathrm{OR}}{1}$} & \multicolumn{2}{|c|}{$95 \% \mathrm{CI}$} \\
\hline & & - & - \\
\hline $201-1,500$ & 3.11 & 1.22 & 9.8 \\
\hline Proportion of homes with UBN in 1993 & 1.02 & 1.01 & 1.04 \\
\hline Proportion of homes with UBN in 1985 & 1.02 & 100 & 1.04 \\
\hline Persons' proportion without education in 1993 & 1.07 & 1.02 & 1.11 \\
\hline Variability of the average of monthly rainfall (standard error every $3 \mathrm{~mm}$ ) & 2.06 & 1.59 & 2.6 \\
\hline Proportion of population older than 45 -year & 0.23 & 0.13 & 0.4 \\
\hline Proportion of people without education in 1985 & 1.03 & 0.99 & 1.06 \\
\hline Investment per capita in the municipality & 1 & 1 & 1 \\
\hline Change in the proportion of homes with UBN between 1985-1993 & 0.97 & 0.93 & 1 \\
\hline Average of monthly rainfall & 1.01 & 1 & 1.01 \\
\hline Change in the people proportion without education between $1985-1993$ & 0.95 & 0.9 & 1.01 \\
\hline
\end{tabular}

$a$ : variables with $\mathrm{p}<0.25 ; b$ : this variable was changed into dichotomic given the better lineal regression with the logic function; $c$ : meters above sea level; CI: confidence interval; OR: odds ratio; UBN: unmet basic needs.

TABLE II

Adjusted odds ratio (OR) of the factors associated with the risk of outbreak in Colombian municipalities, 1987-1994

\begin{tabular}{lccc}
\hline Variables & OR & \multicolumn{2}{c}{$95 \%$ CI } \\
\hline Variability of the average of monthly rainfall (standard error every $3 \mathrm{~mm}$ ) & 1.85 & 1.4 & 2.44 \\
Proportion of population older than 45-year $^{\text {Altitude }}{ }^{a} \leq 200$ & 0.17 & 0.08 & 0.38 \\
$201-1,500$ & 1 & - & - \\
\hline
\end{tabular}

$a$ : meters above sea level; CI: confidence interval.

The multivariate analyses confirmed an association between the proportion of the population older than 45 years and altitude. Also, the risk increased by $85 \%$ when the standard error of monthly rainfall increased by more than $3 \mathrm{~mm}$ and the risk was 3.65 times higher in localities at elevations between 200-1,500 masl than those at elevations of less than 200 masl. No interaction was found among the analysed variables (Table II).

The ROC that we developed demonstrates that the predictive ability for each variable differs (Figs 1-3). The predictive ability also differs when combining any two variables in each possible combination (Figs 4-6). The predictive ability for the three final variables reaches $83.6 \%$ (Fig. 7). This means that a locality with endemic malaria has an increase in the standard error of monthly rainfall of $3 \mathrm{~mm}$, a $5 \%$ decrease in the proportion of the population older than 45 years and an altitude between $200-1,500$ masl, the probability of a malaria outbreak is $83.6 \%$. The most predictive variables are the monthly rainfall variability $(78.4 \%)$ and the proportion of population 45 years or older $(73.7 \%)$ (Figs 1, 2).

\section{DISCUSSION}

We conducted an ecological study with multiple groups to identify factors that predict malaria outbreaks in endemic Colombian municipalities that reported malaria cases from 1987-1994. For the 290 municipalities in our study, the altitude at which the AHM is located, the variability of monthly precipitation and the proportion of inhabitants greater than 45 years of age showed a significant ability to predict malaria outbreaks.

These findings are consistent with those of other researchers, who report a greater influence of geographical location on the transmission of malaria than socioeconomic factors at the ecological level (Gallup \& Sachs 2001). In addition, it was found that environmental phenomena largely explain the differences in levels of transmission between neighbouring regions and the variability of transmission rates within the same area (Matola et al. 1987, Méndez 1995, Camargo et al. 1996, Chang et al. 1997, Gonzalez et al. 1997, Hay et al. 1998, Lindsay \& Martens 1998, Najera et al. 1998, Kleinschmidt et al. 2000, 2001). These results suggest that malaria outbreaks in 


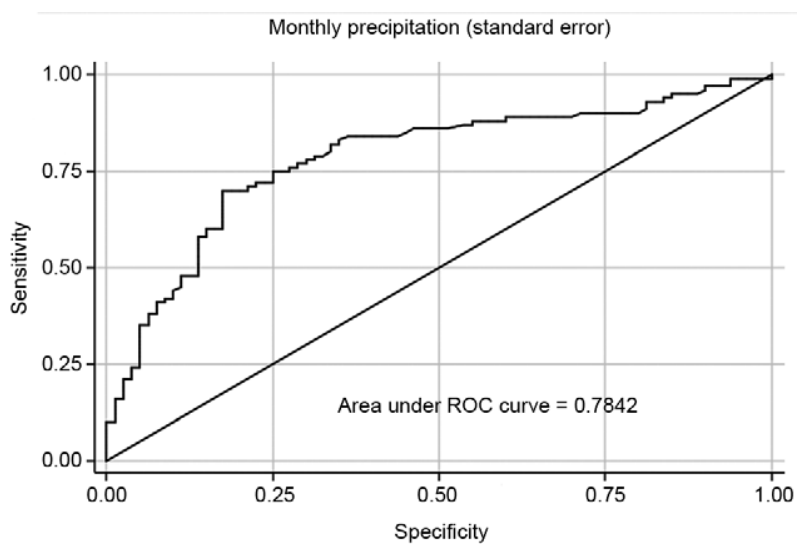

Fig. 1: ROC: receiver operating characteristic curve.

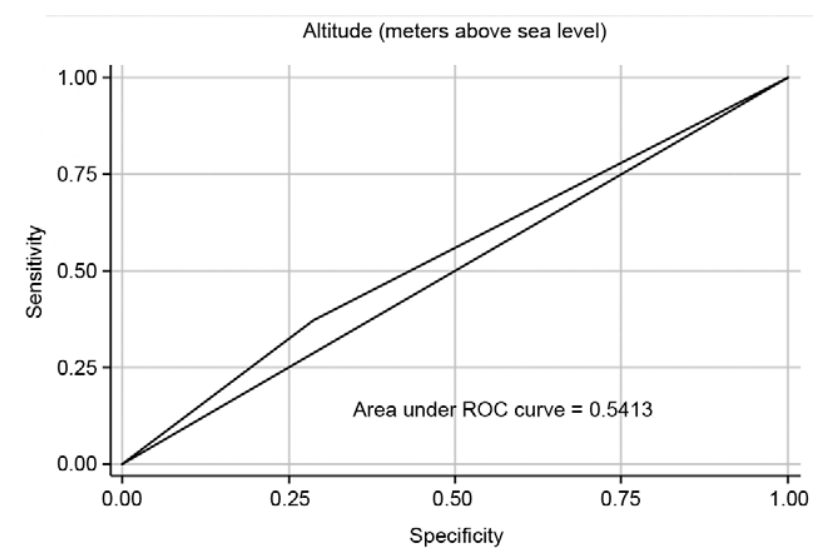

Fig. 3: ROC: receiver operating characteristic curve.

Colombian municipalities are related to environmental and demographic factors and do not appear to interact among them because their predictive ability does not rise greatly when they are simultaneously present (Figs 4-7). Altitude was a weak predictor of outbreaks, probably because the altitude of the AHM does not adequately represent the altitude of the rest of the municipality.

The results were adjusted for population dynamics, climatic conditions, socioeconomic factors and supply of health services in order to control for potential confounders. However, other environmental factors, as temperature, intensity of sunshine and relative humidity and land use factors, such as predominant type of vegetation and the proportion of the area under water, should be examined. Although these factors were not evaluated in this study, the predictive ability of the final model will be enhanced when they are integrated into it. Confounding or interaction could emerge when environmental and land use factors are integrated into the model. If confusion occurs, this will affect the validity of the potential causal factors but will in no way affect their predictive ability, as any confounder does not lose its predictive ability (Szklo \& Nieto 2007b). Moreover,

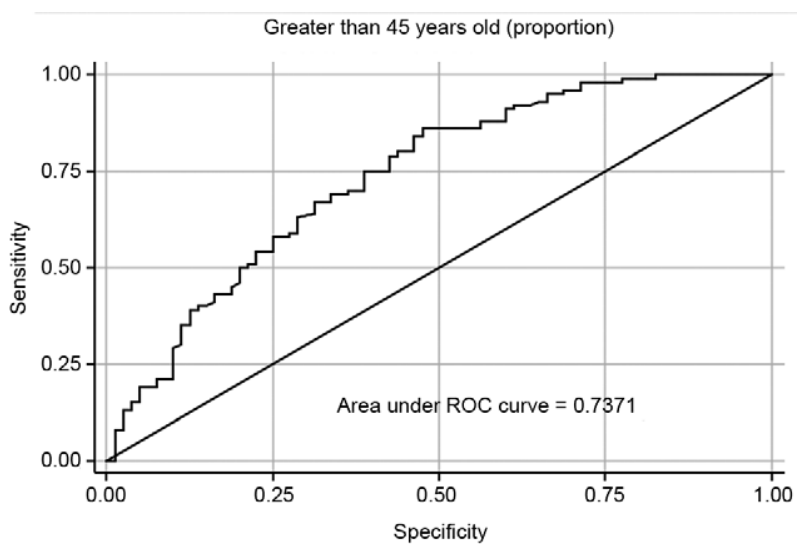

Fig. 2: ROC: receiver operating characteristic curve.

if interaction emerges, the predictive ability of the final model will be increased because is necessary to add multiplicative terms to the model (Szklo \& Nieto 2007a). Thus, the establishment of protocols for collecting data on environmental and land use variables is strongly recommended to improve the predictive capacity of this prototype of EWS.

An increase in the variability of monthly precipitation implies rainy periods followed by periods with less rainfall. This variation could increase vector breeding sites, the vector population and the probability of disease transmission (Najera et al. 1998, Patz 2005).

We also found that municipalities with a greater proportion of people over 45 years of age had fewer malaria outbreaks. This finding correlates with the decline in the incidence of malaria in endemic areas as people age (Baird 1995, Camargo et al. 1996, Woolhouse 1998).

No association was found between local malaria outbreaks and the number of hours per capita that health personnel in the public sector worked, although these variables showed high variability (range 0.006-18.412, median $2.5,95 \% \mathrm{CI} 2.2,2.8)$. One possible explanation is that this variable did not consider the actual time that health personnel devoted to the prevention and control of disease.

During the study period, the decentralisation of health services in Colombia was initiated. The decentralisation increased the transfer of financial resources to municipalities by 6.72 times from 1992-1996. However, there was no relationship the improvement in local resources and local malaria outbreaks, probably because municipalities were not technically prepared to assume the responsibility for malaria control, nor did they have the administrative capacity to implement such interventions. It is also possible that the effects of decentralisation and health sector reform require longer time frames to observe results.

We also observed a great variability in the level of poverty (UBN) between the municipalities studied (range $23.7-97.5 \%$, median $64 \%, 95 \%$ CI 59.9, 66.8), but this variable was not significantly associated with local malaria outbreaks.

Gallup and Sachs (2001) found a similar result in an international ecological analysis and sought to estab- 


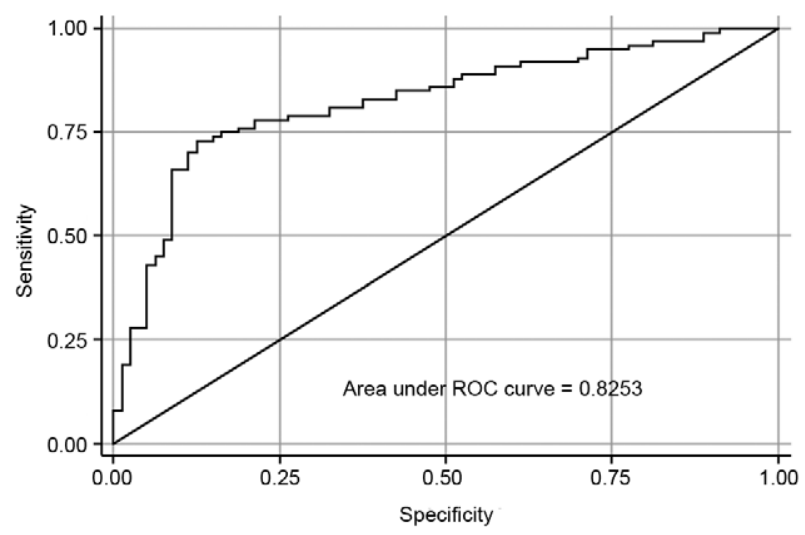

Fig. 4: ROC: receiver operating characteristic curve.

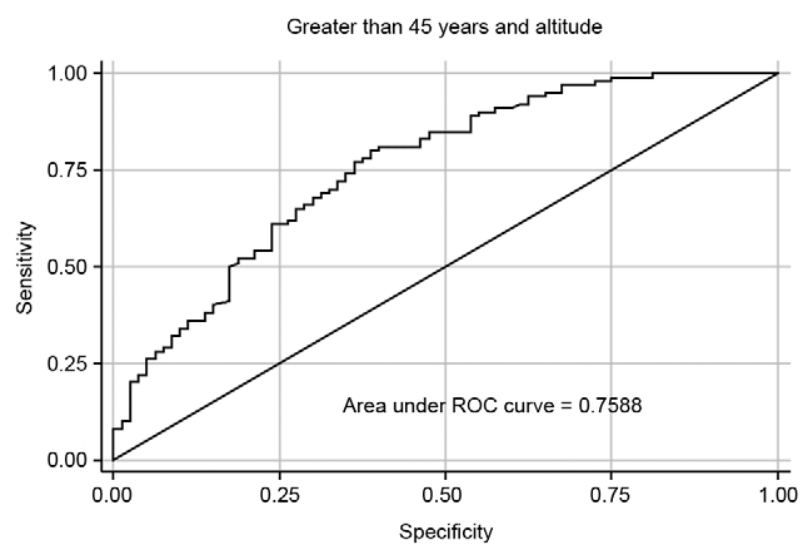

Fig. 6: ROC: receiver operating characteristic curve.

lish the relationship between poverty and the presence of malaria. They found that, when controlling for the history of a region's economic development, malaria is not primarily a disease of poor but that the presence of the illness generates poverty. They also found that the greatest global determinant for malaria distribution is geographical location, which in turn is associated with environmental conditions that are conducive to disease transmission.

Although we excluded municipalities with inadequate malaria reporting processes (23 of 290), defects in the information may persist and the variability of the integrity and of the reporting processes could have generated a misclassification of municipal outbreaks. Nevertheless, is possible to assume that the misclassification was not differential because these defects of information can occur similarly in municipalities with and without malaria outbreaks. Therefore, the associations found may be underestimated, meaning that they could become greater if the flaws in data collection were corrected.

For several decades, environmental and demographic factors have been linked to malaria incidence in Colombia and other countries (Matola et al. 1987, Loevinsohn 1994, Méndez \& Carrasquilla 1995, Bouma et

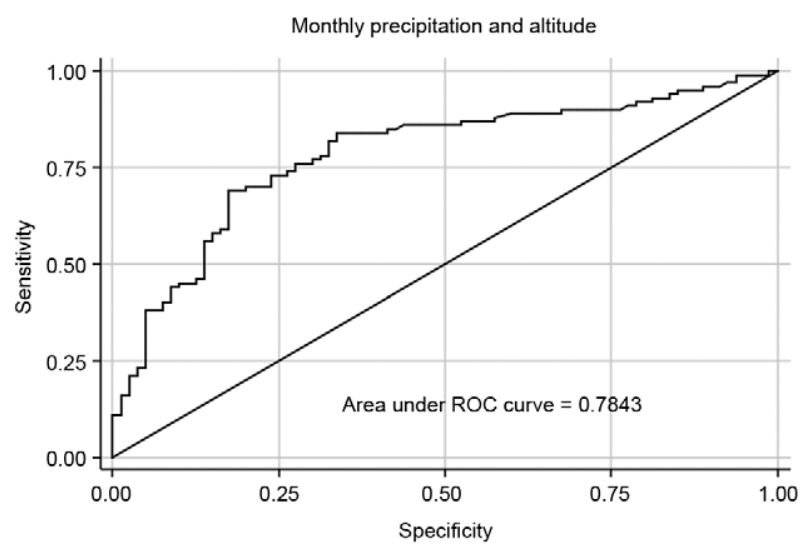

Fig. 5: ROC: receiver operating characteristic curve.

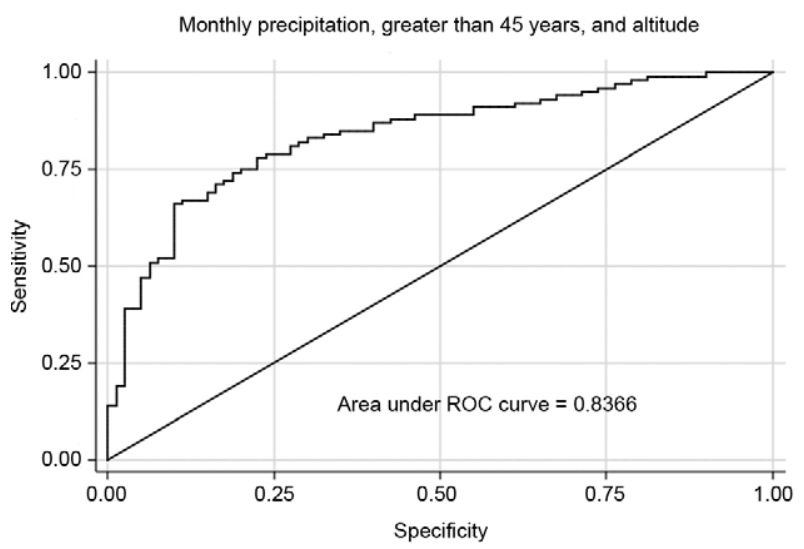

Fig. 7: ROC: receiver operating characteristic curve.

al. 1997, Bouma \& Dye 1997, Ruiz et al. 2006). Hence, our results could be an initial input for a EWS for malaria outbreaks in Colombia. According to these results, if the monthly rainfall varies by a standard error of more than $3 \mathrm{~mm}$, the probability of an outbreak will be $78.4 \%$ (Fig. 1). Additionally, if it is determined, using a national census that the proportion of people older than 45 years has decreased by $5 \%$, the probability of malaria outbreaks increases to $82.5 \%$ (Fig. 4). If those two variables change simultaneously in a municipality whose AHM is between $200-1,500$ masl, the probability of outbreaks is $83.6 \%$. Thus, the establishment of a system to monitor these population factors may be feasible because the information is already being collected by national agencies (DANE and IDEAM) and can then be plugged into a simple mathematical model.

To continue the development of an EWS for malaria outbreaks in Colombia, it is necessary to validate, adjust and standardise the collection of disease, environment and demographic data. One of the biggest weaknesses of current malaria data is its inability to estimate malaria incidence (Guerra et al. 2008). The adjustment of a mathematical model to data does not totally guar- 
antee a good prediction. Thus, it was recently recommended that in the evaluation of the accuracy of all mathematical models that are based on an EWS, comparison of their predictions for the following years with the data for the current year should be made (Chaves \& Pascual 2007). That is, for an EWS model, such as the one proposed here, the accuracy of the mathematical model must be confirmed by identifying the degree of agreement between the outbreak prediction in specific municipalities for the following year and the number of outbreaks that actually occurred in those municipalities for that year.

Another aspect to consider is that the collection of some environmental variables can currently be obtained from remote satellite sensing, such that variables such as relative humidity, vegetation indices and land use can be measured at low cost (Patz 2005). Some countries have already added these variables to models and have improved the malaria prediction capacity (Gomez-Elipe et al. 2007). This collection strategy can create a more accurate EWS and improve its sustainability by avoiding extensive and expensive field campaigns to obtain the necessary data.

This study is proposing an inexpensive and easy-touse method to improve an EWS for malaria outbreaks in developing countries. For the first time, the validity of this model to forecast outbreaks is promising because factors associated with malaria outbreaks in this study have been recognised as predictors of malaria incidence by other authors from countries with endemic malaria. Thus, additional studies are necessary to determine the usefulness of this model from a public health standpoint.

\section{ACKNOWLEDGEMENTS}

To the territorial health staffs, the national archives services and the regional heads of epidemiology offices.

\section{REFERENCES}

Baird JK 1995. Host age as a determinant of naturally acquired immunity to Plasmodium falciparum. Parasitol Today 11: 105-111.

Bouma MJ, Dye C 1997. Cycles of malaria associated with El Nino in Venezuela. JAMA 278: 1772-1774.

Bouma MJ, Poveda G, Rojas W, Chavasse D, Quiñones M, Cox J, Patz J 1997. Predicting high-risk years for malaria in Colombia using parameters of El Niño Southern oscillation. Trop Med Int Health 2: 1122-1127.

Camargo LM, dal Colletto GM, Ferreira MU, Gurgel Sde M, Escobar AL, Marques A, Krieger H, Camargo EP, da Silva LH 1996. Hypoendemic malaria in Rondonia (Brazil, western Amazon Region): seasonal variation and risk groups in an urban locality. $\mathrm{Am}$ J Trop Med Hyg 55: 32-38.

Chang MS, Hii J, Buttner P, Mansoor F 1997. Changes in abundance and behaviour of vector mosquitoes induced by land use during the development of an oil palm plantation in Sarawak. Trans $R$ Soc Trop Med Hyg 91: 382-386.

Chaves LF, Pascual M 2007. Comparing models for early warning systems of neglected tropical diseases. PLoS Negl Trop Dis 1: e33.

DANE - Departamento Administrativo Nacional de Estadística 1985. Metodología de la pobreza en Colombia, Bogotá, 20 pp.
DANE - Departamento Administrativo Nacional de Estadística 1996. Resumen Nacional Censo 1993. Available from: dane.gov.co/index. php?Itemid $=849 \&$ id $=86 \&$ option $=$ com_content\&task $=$ section \#

Fleiss J 1981. Statistical methods for rates and proportions, 2nd ed., John Willey and Sons, New York, p. 138-159.

Fletcher R, Fletcher S 2005. Diagnosis. In: Clinical epidemiology: the essentials, 4th ed., Lippincott Williams \& Wilkins, Philadelphia, p. 35-56.

Gallup JL, Sachs JD 2001. The economic burden of malaria. Am J Trop Med Hyg 64: 85-96.

Gomez-Elipe A, Otero A, van Herp M, Aguirre-Jaime A 2007. Forecasting malaria incidence based on monthly case reports and environmental factors in Karuzi, Burundi, 1997-2003. Malar J 6: 129.

Gonzalez JM, Olano V, Vergara J, Arevalo-Herrera M, Carrasquilla G, Herrera S, Lopez JA 1997. Unstable, low-level transmission of malaria on the Colombian Pacific coast. Ann Trop Med Parasitol 91: 349-358.

Guerra CA, Gikandi PW, Tatem AJ, Noor AM, Smith DL, Hay SI, Snow RW 2008. The limits and intensity of Plasmodium falciparum transmission: implications for malaria control and elimination worldwide. PLoS Med 5: e38.

Hay SI, Snow RW, Rogers DJ 1998. Predicting malaria seasons in Kenya using multitemporal meteorological satellite sensor data. Trans R Soc Trop Med Hyg 92: 12-20.

Hosmer D, Lemeshow S 1989. Applied logistic regression, John Wiley \& Sons, New York, 150 pp.

IGAC - Instituto Geográfico Agustín Codazzi 1996. Diccionario geográfico de Colombia, 3rd ed., Ministerio de Hacienda y Crédito Público de Colombia, Bogotá, 2524 pp.

Kleinschmidt I, Bagayoko M, Clarke GP, Craig M, Le Sueur D 2000. A spatial statistical approach to malaria mapping. Int $J$ Epidemiol 29: 355-361.

Kleinschmidt I, Sharp BL, Clarke GPY, Curtis B, Fraser C 2001. Use of generalized linear mixed models in the spatial analysis of small-area malaria incidence rates in Kwazulu Natal, South Africa. Am J Epidemiol 153: 1213-1221.

Lemeshow S, Hosmer DW Jr 1982. A review of goodness-of-fit statistics for use in the development of logistic regression models. $\mathrm{Am}$ J Epidemiol 115: 92-106.

Lindsay SW, Martens WJ 1998. Malaria in the African highlands: past, present and future. Bull World Health Organ 76: 33-45.

Loevinsohn ME 1994. Climatic warming and increased malaria incidence in Rwanda. Lancet 343: 714-718.

Lora E 2005. Índices de precios y cantidades. In: Técnicas de medición económica: Metodologia y aplicaciones en Colombia, 3rd ed., Alfaomega Grupo Editor, Bogotá, p. 63-103.

Matola YG, White GB, Magayuka SA 1987. The changed pattern of malaria endemicity and transmission at Amani in the eastern Usambara mountains, north-eastern Tanzania. J Trop Med Hyg 90: 127-134.

Mauny F, Viel JF, Handschumacher P, Sellin B 2004. Multilevel modelling and malaria: a new method for an old disease. Int $J$ Epidemiol 33: 1337-1344.

Méndez F, Carrasquilla JG 1995. Epidemiología de la malaria en el área urbana de Buenaventura: análisis de la ocurrencia en el periodo 1987-1993. Colomb Med 26: 77-85.

Morabia A 1996. From disease surveillance to the surveillance of risk factors. Am J Public Health 86: 625-627.

Morgenstern H 2008. Ecologic studies. In K Rothman, S Greenland, T Lash, Modern epidemiology, 3rd ed., Lippincott Williams \& Wilkins, Philadelphia, p. 511-531. 
Najera J, Koumetsov R, Dellacollette C 1998. Malaria epidemics: detection and control, forecasting and prevention, WHO, Geneve, $87 \mathrm{pp}$.

Patz J 2005. Satellite remote sensing can improve chances of achieving sustainable health. Environ Health Perspect 113: A84-85.

Rehle T, Lazzari S, Dallabetta G, Asamoah-Odei E 2004. Secondgeneration HIV surveillance: better data for decision-making. Bull World Health Organ 82: 121-127.

Ruiz D, Poveda G, Velez ID, Quinones ML, Rua GL, Velasquez LE, Zuluaga JS 2006. Modelling entomological-climatic interactions of Plasmodium falciparum malaria transmission in two Colombian endemic-regions: contributions to a National Malaria Early Warning System. Malar J 5: 66.

Singh N, Singh OP, Sharma VP 1996. Dynamics of malaria transmission in forested and deforested regions of Mandla district, central India (Madhya Pradesh). J Am Mosq Control Assoc 12: 225-234.
Szklo M, Nieto F 2007a. Defining and assessing heterogeneity of effects: interaction. In M Szklo, F Nieto, Epidemiology. Beyond the basics, 2nd ed., Jones and Bartlett Publishers, Boston, p. 183-223.

Szklo M, Nieto F 2007b. Identifying noncausal associations: confounding. In M Szklo, F Nieto, Epidemiology. Beyond the basics, 2nd ed., Jones and Bartlett Publishers, Boston, p. 151-181.

Teutsch SM, Churchill RE 2000. Principles and practice of public health surveillance, 2nd ed., Oxford University Press, Oxford, 406 pp.

Thompson R, Begtrup K, Cuamba N, Dgedge M, Mendis C, GamageMendis A, Enosse SM, Barreto J, Sinden RE, Hogh B 1997. The Matola malaria project: a temporal and spatial study of malaria transmission and disease in a suburban area of Maputo, Mozambique. Am J Trop Med Hyg 57: 550-559.

Woolhouse ME 1998. Patterns in parasite epidemiology: the peak shift. Parasitol Today 14: 428-434. 